\title{
Research on the Impact of Online Review on Consumers' Booking Decisions
}

\author{
Nian Zhao \\ Business School \\ Sichuan Agricultural University \\ Dujiangyan, China \\ Linbin Zhang \\ Business School \\ Sichuan Agricultural University \\ Dujiangyan, China
}

\author{
Xiaolin $\mathrm{Li}$ \\ Business School \\ Sichuan Agricultural University \\ Dujiangyan, China \\ You Li \\ Business School \\ Sichuan Agricultural University \\ Dujiangyan, China
}

\begin{abstract}
E-commerce is a business activity centered on information network technology and centered on commodity exchange. It is the electronic, network and informatization of all aspects of traditional business activities. With the continuous development of the Internet technology, the ecommerce model with changes will continue to impact on the original business model, form a partial change, and at the same time have an impact on the consumer's consumer behavior, but also in the commercial activities. This process is a cycle. Finally, it forms a stable business model. With the expansion of the scale of Internet users in China and the diversification of business models for online travel services, research on consumers' online booking behavior has gradually become a hot topic in the research field. In order to understand the research status of domestic and foreign scholars in this field, the author conducted the words "consumer booking", "online review", "online review", and "reservation" in domestic and foreign mainstream databases such as CNKI, Wanfang Database and Elsevier. Topic and keyword search, and collate the retrieved documents, the following review of these documents, with a view to provide ideas for research ideas and business decisions.
\end{abstract}

Keywords-e-WOM; online reviews; booking decisions

\section{INTRODUCTION}

E-commerce is a business activity centered on information network technology and centered on commodity exchange. It is the electronic, network, and informatization of all aspects of traditional business activities. With the continuous development of the Internet technology, the ecommerce model with changes will continue to impact on the original business model, form a partial change, and at the same time have an impact on the consumer's consumer behavior, but also in the commercial activities. This process is a cycle. Finally, it forms a stable business model. With the expansion of the scale of Internet users in China and the diversification of business models for online travel services, research on consumers' online booking behavior has gradually become a hot topic in the research field. In order to understand the research status of domestic and foreign scholars in this field, the author conducted the words "consumer booking", "online review", "online review", and "reservation" in domestic and foreign mainstream databases such as CNKI, Wanfang Database, and Elsevier. Topic and keyword search, and collate the retrieved documents, the following review of these documents, with a view to provide ideas for research ideas and business decisions.

\section{THE CONCEPT OF ONLINE REVIEW AND BOOKING DECISIONS}

E-WOM is the exchange and communication between consumers and consumers on the characteristics of products or services, experience in use, and providers' information [1] Online commentary is a common expression of e-WOM. It is a special type of e-WOM that evolved from the traditional offline e-WOM and emerged with the advent of the Internet. It is a product that is posted on a company website or a third party website. Or service evaluation. The importance of word-of-mouth has been widely recognized by experts and operators. In the third industry, word-of-mouth represents the experience and experience of past consumers. It is of great reference value for potential consumers to make decisions, mainly reflected in potential consumers. The initial impressions of the purchase and the decision-making behavior after purchase have a very important role. The reason why consumers are influenced by e-WOM is mainly based on the following two considerations: On the one hand, consumers believe that the reputation of the commercial products and services that they may purchase can provide reliable information from other consumers, compared with the promotion of businesses. It can accurately reflect the true quality and value of the product; on the other hand, it derives from the psychological traits of the consumer. For unfamiliar goods, it is further influenced by the pressure of social groups [2] and is bought in order to improve social cognition.

For experiential products such as tourism and sightseeing, hotel accommodation, because of the intangible nature of 
their products, it is difficult for consumers to evaluate them before consumption. Therefore, when booking online, the impact of electronic e-WOM is particularly important [3]. Online commentary, as an important expression of e-WOM, has an important influence on making reservation decisions for consumers who use the Internet. From the consumer's behavior stage, the online booking process of Chinese travel website users is mainly divided into online information search, purchase behavior, online order submission, online/offline payment and the basic implementation of the booking process. With regard to the concepts of online reviews and online booking, the concepts of comprehensive related literature are summarized and summarized in "Table I" and "Table II".

\section{TABLE I. THE CONCEPT OF ONLINE REVIEW}

\begin{tabular}{|c|c|}
\hline The author & The Concept of Online review \\
\hline $\begin{array}{l}\text { Tan } \\
\text { Qianxia } \\
(2013)\end{array}$ & $\begin{array}{l}\text { Online commentary is a form of online word-of-mouth. } \\
\text { Internet word-of-mouth refers to the way in which } \\
\text { consumers place information on board information } \\
\text { products such as corporate website message boards, } \\
\text { express their opinions, and express positive negative } \\
\text { emotions on the company's products or services [4]. }\end{array}$ \\
\hline $\begin{array}{l}\text { Guo } \\
\text { Guoqing } \\
(2010)\end{array}$ & $\begin{array}{l}\text { Online commentary is an emerging source of } \\
\text { independent product information. It is a product that } \\
\text { consumers publish on the Internet or on the platform } \\
\text { and evaluates the product mainly in the form of text, } \\
\text { including praises, complaints about the product, or } \\
\text { personal purchases of specific products or services. } \\
\text { And use feelings [5]. }\end{array}$ \\
\hline $\begin{array}{l}\text { Brian T. } \\
\text { Ratchford } \\
(2001)\end{array}$ & $\begin{array}{l}\text { Online reviews are platforms that allow consumers to } \\
\text { post personal product opinions and may exist on } \\
\text { commercial sales websites, product websites, personal } \\
\text { homepages, or consumer complaints. Unlike other } \\
\text { forms of online word-of-mouth, online reviews are an } \\
\text { online word-of-mouth information that consumers can } \\
\text { easily obtain [6]. }\end{array}$ \\
\hline $\begin{array}{c}\text { Tsao W } \quad \text { C } \\
(2014)\end{array}$ & $\begin{array}{l}\text { Defining an online comment as any potential positive } \\
\text { or negative consumer's positive or negative statement } \\
\text { of the product can be obtained via the Internet by most } \\
\text { people and public institutions [7]. }\end{array}$ \\
\hline $\begin{array}{l}\text { Zhou } \\
\text { Jingjing } \\
(2010)\end{array}$ & $\begin{array}{l}\text { Online reviews refer to the positive or negative views } \\
\text { of a customer on a shopping site or other review site or } \\
\text { forum for a product or service. This view can be based } \\
\text { on one's own experience or the experience of others [8]. }\end{array}$ \\
\hline
\end{tabular}

${ }^{\text {a. }}$ Source: The author organizes according to relevant literature

TABLE II. THE CONCEPT OF BOOKING DECISIONS

\begin{tabular}{|c|l|}
\hline $\begin{array}{c}\text { The author } \\
\text { (2010) }\end{array}$ & \multicolumn{1}{|c|}{ The Concept of Online review Reservation } \\
& $\begin{array}{l}\text { Decision-making refers to the use of scientific methods } \\
\text { and means to select a more satisfactory solution from } \\
\text { two or more alternatives to achieve the desired goal. } \\
\text { On-line booking is a form of consumer decision- } \\
\text { making [9]. }\end{array}$ \\
\hline $\begin{array}{l}\text { Zhu Jingyu } \\
\text { (2014) }\end{array}$ & $\begin{array}{l}\text { Reservations occur before consumers actually use the } \\
\text { consumption, mainly involving problem identification, } \\
\text { information gathering, program evaluation, and } \\
\text { decision-making before the decision-making process. }\end{array}$ \\
$\begin{array}{l}\text { Online booking refers to all the behaviors of people } \\
\text { during the process of booking goods through the }\end{array}$ \\
$\begin{array}{l}\text { Internet platform. The booking decision is a process } \\
\text { with multiple continuous behaviors (including } \\
\text { continuous psychological activities and behavior } \\
\text { changes) [10]. }\end{array}$ \\
\hline
\end{tabular}

\begin{tabular}{|l|l|}
\hline The author & \multicolumn{1}{|c|}{ The Concept of Online review Reservation } \\
\hline $\begin{array}{c}\text { Marina } \\
(2015)\end{array}$ & $\begin{array}{l}\text { Online booking refers to consumers' pre-ordering of a } \\
\text { service or commodity through an online platform [11] }\end{array}$ \\
\hline $\begin{array}{l}\text { Song } \\
\text { Yuanyuan } \\
(2015)\end{array}$ & $\begin{array}{l}\text { Online booking means that consumers choose to pre- } \\
\text { book online or on the phone, and online travel service } \\
\text { providers provide tourism products or services such as } \\
\text { hotels, attraction tickets, air tickets, etc., and pay online } \\
\text { or pay in physical stores [12]. }\end{array}$ \\
\hline
\end{tabular}

Source: The author organizes according to relevant literature

\section{A. The Relationship Between Online Reviews and Consumer Reservation}

Foreign scholars have begun to study the online booking behavior of tourism consumption earlier. Changes in the consumption behavior of tourism in the Internet age have been seen in the study theory of consumer behavior. The research on the impact of online reviews on consumer booking decisions focuses primarily on exploring the characteristics of online reviews by exploiting their impact; as the study progresses, scholars begin to investigate the internal factors that influence the impact of online reviews on consumer booking decisions. For the relationship between online reviews and consumer reservation, the author will summarize the three aspects of the mediation and adjustment factors between the text features of online reviews, consumer characteristics, and the impact of online reviews on consumer Reservation.

The study of the impact of textual features of online reviews on consumers first began with the discussion of the promotion of online reviews on the sale of goods or services. By comparing Amazon.com's book sales information, J. Chevalie and D. Mayzlin (2006) pointed out that there is a strong relationship between emotional bias of online reviews and book sales, because consumers are more inclined to make decisions based on negative reviews, that is, negative reviews. The impact is greater than the impact of positive review content [13]. For research on consumer reservations, Seegers and Vermeuren (2009) found that positive online reviews can improve the overall impression of consumers on the hotel, especially for those less-famous economy hotels, the improvement effect will be more apparent [14]. Ye et al. (2009) found that positive online reviews helped to increase online bookings for the entire hotel. At the same time, extreme online reviews or frequently-changing online reviews had a significant negative impact on the number of online bookings for hotels [15]. Utz (2012) and others have tapped more than 1,000 reviews on e-Bay. Through data analysis, it has been found that positive reviews and negative reviews have a significant impact on merchants' trust and the price premium consumers are willing to pay for consumers' willingness to make reservations [16]. Yu Hang (2014) explored the impact of online reviews on consumer buying intentions, and found that the quality of comments and the number of reviews have a very significant impact on consumer buying intentions, and that this effect also applies to consumer booking situations [17]. Han Yanyan et al. (2014) used meta-analysis to find that for experiential products (such as hotels), the perceived usefulness of review valences for consumers is more significant, further affecting consumers' willingness to make experiential products [18]. Wen-Chin et al. (2015) research shows that positive online 
reviews are more useful than negative online reviews, and positive online reviews can effectively increase the volume of reservations and reviews. At the same time, it proves that electronic e-WOM enhances consumers' willingness to make impact on reservations. [19]. Zhang Ying (2015) studied the impact of online hotel reviews on consumer booking decisions in terms of quantity, scores, timeliness, and content of online reviews, and finally concluded that review scores and reviews have positive effects on consumer booking decisions. The earlier the release is done, the more referential to the consumer it is, and the more significant its effect on the booking intention will be [20].

The research of Pan LY, Chiou JS (2011) found that the demographic characteristics and commentary experience level of consumers who published the comments all had a certain impact on the online commentary behavior, and the main body of the online commentary issuer was spent more time online. Young people [21]. Toh (2011) found that compared with male consumers, female consumers prefer to obtain relevant information about products by browsing online reviews. At the same time, their research shows that most people are relatively young and have a Considerable income, so compared with the traditional consumption channels, they make more online reservations [22]. Bao Fuyuan (2013) analyzed the characteristics of online booking consumers in terms of age distribution, income range, education level, and booking frequency. The study found that young netizens aged 18 to 35 accounted for the majority of travelers, and Internet bookers were mostly It is a highincome group with a high level of education, a low rate of member reservations, and low customer loyalty (re-booking) [23]. Zhang Jian (2014) adopts an empirical analysis method, arguing that the degree to which online review publishers publish experience (the number of times and frequency of publish reviews is considered to be experienced) has no significant effect on consumers' willingness to subscribe [24].

With the in-depth study of the influence of online reviews on consumers' willingness to book, scholars have gradually found that online reviews influence the consumers' perceived usefulness, perceived ease of use, and perceived risk, thereby affecting their booking intention. At the same time, it was found that other factors will regulate this effect, mainly reflected in the adjustment of two factors: product characteristics (brands, stars, etc.) and consumers (psychological factors, experience level, professional ability, etc.).

Matzler (2006) believed that the usefulness of reviews was a key factor that influences consumers to make reservation decisions, drove customer emotions, and influenced customer reservation decisions [25]. Wen Lijia (2012) based on the technology acceptance model, according to the online travel booking model described by him, concluded that perceived usefulness and perceived ease of use have a positive effect on consumer attitudes [26]. Zhang Jian (2014) started from the perspective of product type and consumer experience, combined with the characteristics of online travel in China, and conducted in-depth research on perceived risks and booking intentions. As a result, he found that the booking intention of experienced customers is stronger than that of inexperienced customers. The reservation intention of simple products is stronger than that of complex products [24]. Park (2015) found that lowinvolvement consumers are more likely to make decisions based on the number of online reviews, while highly involved consumers are more likely to be influenced by the emotional polarity of comments when making decisions [27]. Wen-Chin Tsao (2015) investigated the effect of consumer psychology on the influence of hotel reviews on hotel reservations through questionnaire surveys and simulation experiments. The results show that reading positive evaluations for congenial consumers compared to ordinary consumers. There is a strong influence in booking intentions [28]. Li Yujie (2015) found that compared with consumers with low involvement, highly involved consumers have more intense interest in products because of their higher interest, and their purchase intentions are also more susceptible to the quality of comments; in addition, due to professional knowledge High-level consumers are more knowledgeable about products in online reviews than those with lower levels of expertise, so they are more susceptible to the quality of reviews [29]. As far as the overall trend is concerned, with the gradual deepening of research on online consumer behavior, the level of research on consumer booking behavior is constantly deepening, and research themes are also being refined.

\section{B. An Intergrated Framework for Online Reviews on the Influence of Consumer's Willingness to Book}

This article collates relevant literature on the impact of online reviews on consumer booking decisions and concludes with a research framework model, as shown in the "Fig. 1":

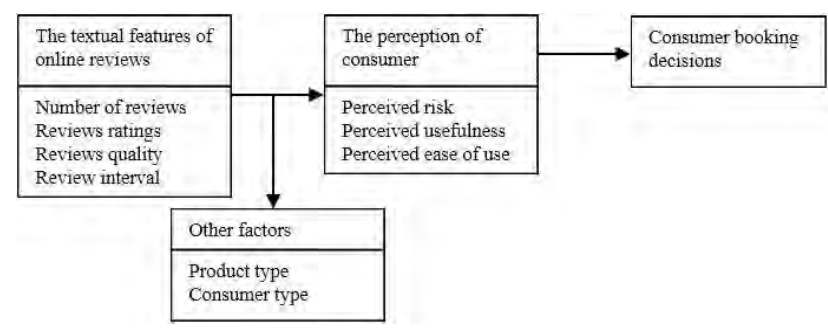

Fig. 1. An integrated framework for online reviews on the influence of consumers' willingness to book.

The theoretical framework includes four parts: online review features, booking decisions, consumer perception, and other factors. Online review features have an impact on predetermined decisions; consumer perception as a mediator affects the role of online review features on predetermined decisions; and other factors as a moderator affect the role of online review features in predetermined decisions.

\section{RESEARCH REVIEW}

Due to the fact that domestic online bookings have only begun to develop in recent years and become an important choice for popular consumption, it has become a short time for domestic research, so domestic related research is relatively inadequate; in contrast, foreign scholars have more 
research content broad, deeper, and forward-looking. The comparison found that domestic scholars mainly explored the behavioral characteristics of online travel consumers, and the cumulative accumulation of relevant literature was even more lacking than that of foreign studies. There were many qualitative and in-depth studies and their participation in motivation, process, psychological mechanism and selfmaturity were studied. The depth is still insufficient. There is a serious lack of research on online commentators. The above aspects are to be supplemented by subsequent scholars. Most of the studies have involved the discussion of online booking behavior characteristics and influencing factors, but no mature research system has yet been formed. For research methods, domestic research methods are similar to those of foreign countries. Most scholars use empirical research methods, quantitative analysis methods, questionnaires, or statistical methods to conduct research. In the field of empirical research, statistical analysis is the main research method, especially in the current study of online consumer behavior, one of the most widely used methods. In addition, as far as research variables are concerned, scholars have studied the impact of online reviews on consumer booking decisions from different perspectives and selecting different variables. However, most of them are selected individually and studied individually. The boundaries of these variables are not very significant. Clearly, there are a lot of repetitive crossover situations. For future research, this paper proposes to systematically define existing variables and form a more unified framework so that research can be conducted more effectively and systematically, with a view to achieving better progress in theory and practice.

\section{CONCLUSION}

In summary, in terms of the research on the influence of consumers' willingness to book, most of the research objects are for experiential products, such as hotel reservations, and there is less research on other types of products. This may be related to the characteristics of the product itself. It can be considered that the hotel industry is relatively common and involves a large number of consumers. They generally refer to relevant website information and product review information before making reservation decisions, thus having a profound significance in this research. Most of the literature studies are based on the effect of hotel type (brand, star rating) and consumer type adjustment, and the single review text feature may have impact on consumer bookings, lacking the number of reviews, polarity, valence, etc. The role of research on the impact of consumer bookings, and subsequent research can be extended in the above aspects. In terms of research models and theoretical basis, most of the content is based on rational behavior theory, theory of planned behavior, and technology acceptance model as the theoretical basis for research. The scales of perceived risk, perceived usefulness, perceived ease of use, and willingness to make reservations involved in the study are studied. Relatively mature development can be used as a reference for later researchers. However, most of the scales used are derived from the research results of foreign scholars. It is still unclear whether the influence factors (such as face culture, etc.) with Chinese economic and social characteristics are suitable. Therefore, future research can start from these aspects.

\section{REFERENCES}

[1] Fu Yi. A Survey of Internet E-WOM Research [J]. Modern Business, 2008, (30): 177-179

[2] Bearden W.O \& Rose R.L, Attention to social comparison information: an individual difference factor affecting consumer conformity [J], Journal of Consumer Research, 1990,16(4): 461-471

[3] Litvina S.W \& Goldsmith R.E.\& Pan B. Electronic word-of-mouth in hospitality and tourism management [J]. Tourism Management, 2008, (29): 458-468.

[4] Tan Qianxia. Study on the Impact of Online Comments on Consumers' Purchase Intention [D]. Hunan University, 2013.

[5] Guo Guoqing,Chen Kai,He Fei.Research on the Influencing Factors of Credibility of Consumer Online Reviews[J]. Contemporary Economic Management, 2010, 32(10):17-23.

[6] Brian T. Ratchford, Debabrata Talukdar, Myung-Soo Lee. A Model of Consumer Choice of the Internet as an Information Source[J]. International Journal of Electronic Commerce, 2001, 5(3):7-21.

[7] Tsao W C. Which type of online review is more persuasive? The influence of consumer reviews and critic ratings on moviegoers[J]. Electronic Commerce Research, 2014, 14(4):559-583.

[8] Zhou Jingjing. Research on the influence of online customer reviews on consumer purchasing decisions [D]. Zhejiang University, 2010.

[9] Zhou Yanli. Research on Information Structure of Online Consumer Purchase Decision [D]. Shandong University, 2010.

[10] Jingjing Zhu. Research on online booking behavior of travel website users[D]. East China Normal University, 2014.

[11] Malina H. Customer Online Booking Behavior Analysis and Marketing Strategy [D]. Shenyang Normal University, 2015.

[12] Song Yuanyuan. Research on online hotel booking willingness based on technology acceptance model[D]. Hunan Normal University, 2015.

[13] J. Chevalier, D. Mayzlin. The Effect of E-WOM Online: Online Book Reviews[J].Journal of Marketing Research. 2006,43(3): 345-354.

[14] Vermeulen I E, Seegers D. Tried and tested: the impact of online hotel reviews on consumer consideration.[J]. Tourism Management, 2009, 30(1):123-127

[15] Ye Q, Law R, Gu B. The impact of online user reviews on hotel room sales[J]. International Journal of Hospitality Management, 2009, 28(1):180-182.

[16] Utz S, Kerkhof P, Joost V D B. Consumers rule: How consumer reviews influence perceived trustworthiness of online stores[J]. Electronic Commerce Research \& Applications, 2012, 11(1):49-58.

[17] Yu Hang. Research on the Impact of Internet E-WOM on Consumers' Purchase Intention [D]. Central China Normal University, 2014.

[18] Fang Wenmin, Zhang Ning, Han Yanyan. Research Review of Online Review Information Mining[J]. Journal of Information Resources Management, 2016(1):4-11.

[19] Purnawirawan N, Eisend M, Pelsmacker P D, et al. A Meta-analytic Investigation of the Role of Valence in Online Reviews[J]. Journal of Interactive Marketing, 2015, 31:17-27.

[20] Zhang Ying. Research on the impact of online hotel reviews on consumer booking decisions[D]. Hebei Normal University, 2015.

[21] Pan LY, Chiou JS. How much can you trust online in-formation? Cues forperceived trustworthiness of consumergenerated online information[J]. Journal of Interactive Marketing, 2011, 25(02):67-74.

[22] Toh R S, Dekay C F, Raven P. Travel planning: searching for and booking hotels on the internet.[J]. Cornell Hospitality Quarterly, 2011, 52(4):388-398

[23] Bao Fuyuan.Review of China's Tourism Website Research(2000 2011)[J].Journal of Leshan Teachers College, 2013, 28(02): 102-105.

[24] Zhang Hao. Analysis of online travel perception risk and booking behavior[D]. University of Science and Technology of China, 2014. 
[25] Matzler K, Waiguny M, Toschkov A et al. Usability, Emotions andCustomer Satisfaction in Online Travel Booking[M]. Information andCommunication Technologies in Tourism 2006, Dr.Hitz M, Dr. Sigala M, Dr. Murphy J, 2006, 135-146.

[26] Wen Lijia. Study on Consumers' Booking Intention and Market Delivery in Online Travel in China[D]. Nanchang University, 2012.

[27] Sangwon Park, Juan L. Nicolau. Asymmetric effects of onlineconsumer reviews[J]. Annals of Tourism Research, 2015, 50(01): 67-83.

[28] Tsao W C, Hsieh M T, Shih L W, et al. Compliance with eWOM: The influence of hotel reviews on booking intention from the perspective of consumer conformity[J]. International Journal of Hospitality Management, 2015, 46(April): 99-111.

[29] Li Yujie, Liao Chenglin, Li Yi. A Study on the Influence Mechanism of Consumer Individual Behavior Preference on the Validity of Online Comments[J]. Soft Science, 2015 (1): 105-109. 